\title{
Is autumn the key for dengue epidemics in non endemic regions? The case of Argentina
}

\author{
Anibal E Carbajo ${ }^{1,2}$, Maria V Cardo ${ }^{\text {Corresp., }}{ }_{1,2}$, Pilar C Guimarey ${ }^{3}$, Arturo A Lizuain ${ }^{3}$, Maria P Buyayisqui ${ }^{4}$, \\ Teresa Varela $^{4}$, Maria E Utgés ${ }^{3}$, Carlos M Giovacchini ${ }^{4}$, Maria S Santini ${ }^{3}$ \\ 1 Universidad Nacional de San Martin, Instituto de Investigacion e Ingenieria Ambiental, Laboratorio de Ecologia de Enfermedades Transmitidas por \\ Vectores, General San Martin, Buenos Aires, Argentina \\ 2 Consejo Nacional de Investigaciones Cientificas y Tecnicas, Argentina \\ 3 Centro Nacional de Diagnóstico e Investigación en Endemo-epidemias CeNDIE - ANLIS, Ministerio de Salud de la Nacion, Buenos Aires, Argentina \\ 4 Área de Vigilancia de la Salud, Dirección de Epidemiología, Ministerio de Salud de la Nación, Buenos Aires, Argentina \\ Corresponding Author: Maria V Cardo \\ Email address: mcardo@unsam.edu.ar
}

Background. Dengue is a major and rapidly increasing public health problem. In Argentina, the southern extreme of its distribution in the Americas, epidemic transmission takes place during the warm season. After its re-emergence in 1998 two major outbreaks have occurred, the biggest during 2016. To identify the environmental factors that trigger epidemic events, we analyzed the occurrence and magnitude of dengue outbreaks in time and space at different scales in association with climatic, geographic and demographic variables and number of cases in endemic neighboring countries.

Methods. Information on dengue cases was obtained from dengue notifications reported in the National Health Surveillance System. The resulting database was analyzed by Generalized Linear Mixed Models under three methodological approaches, to identify in which years the most important outbreaks occurred in association with environmental variables and propose a risk estimation for future epidemics (temporal approach); characterize which variables explain the occurrence of local outbreaks through time (spatio-temporal approach); and select the environmental drivers of the geographical distribution of dengue positive districts during 2016 (spatial approach).

Results. Within the temporal approach, the number of dengue cases country-wide between 2009 and 2016 was positively associated with the number of dengue cases in bordering endemic countries and negatively with the days necessary for transmission (DNT) during the previous autumn in the central region of the country. Annual epidemic intensity in the period 1999-2016 was associated with DNT during previous autumn and winter. Regarding the spatio-temporal approach, dengue cases within a district were also associated with mild conditions in the previous autumn along with the number of dengue cases in neighboring countries. As for the spatial approach, the best model for the occurrence of two or more dengue cases per district included autumn minimum temperature and human population as fixed factors, and Province as a grouping variable. Explanatory power of all models was high, in the range 57-95\%.

Discussion. Given the epidemic nature of dengue in Argentina, virus pressure from endemic neighboring countries along with climatic conditions are crucial to explain disease dynamics. In the three methodological approaches, temperature conditions during autumn were best associated with dengue patterns. We propose that mild autumns represent an advantage for mosquito vector populations and that, in temperate regions, this advantage manifests as a larger egg bank from which the adult population will re-emerge in spring. This may constitute a valuable anticipating tool for high transmission risk events. 


\section{Is autumn the key for dengue epidemics in non endemic regions? The case of} 2 Argentina.

3

4 Aníbal E. Carbajo ${ }^{1,2}$, María V. Cardo ${ }^{1,2}$, Pilar C. Guimarey³, Arturo A. Lizuain ${ }^{3}$, María P. 5 Buyayisqui ${ }^{4}$, Teresa Varela ${ }^{4}$, María E. Utgés ${ }^{3}$, Carlos M. Giovacchini ${ }^{4}$, María S. Santini ${ }^{3}$

$6{ }^{1}$ Universidad Nacional de San Martín, Instituto de Investigación e Ingeniería Ambiental, 7 Laboratorio de Ecología de Enfermedades Transmitidas por Vectores, General San Martín, 8 Buenos Aires, Argentina

$9 \quad{ }^{2}$ Consejo Nacional de Investigaciones Científicas y Técnicas, Argentina

$10{ }^{3}$ Centro Nacional de Diagnóstico e Investigación en Endemo-epidemias CeNDIE-ANLIS11 Ministerio de Salud de la Nación, Argentina

$12{ }^{4}$ Área de Vigilancia de la Salud, Dirección de Epidemiología, Ministerio de Salud de la Nación, 13 Argentina

15 Corresponding Author:

16 María V. Cardo ${ }^{1,2}$

17

18 Email address: mcardo@unsam.edu.ar 
ABSTRACT

21 Background. Dengue is a major and rapidly increasing public health problem. In Argentina, the southern extreme of its distribution in the Americas, epidemic transmission takes place during the warm season. After its re-emergence in 1998 two major outbreaks have occurred, the biggest during 2016. To identify the environmental factors that trigger epidemic events, we analyzed the occurrence and magnitude of dengue outbreaks in time and space at different scales in association with climatic, geographic and demographic variables and number of cases in endemic neighboring countries.

Methods. Information on dengue cases was obtained from dengue notifications reported in the National Health Surveillance System. The resulting database was analyzed by Generalized Linear Mixed Models under three methodological approaches, to identify in which years the most important outbreaks occurred in association with environmental variables and propose a risk estimation for future epidemics (temporal approach); characterize which variables explain the occurrence of local outbreaks through time (spatio-temporal approach); and select the environmental drivers of the geographical distribution of dengue positive districts during 2016 (spatial approach).

Results. Within the temporal approach, the number of dengue cases country-wide between 2009 and 2016 was positively associated with the number of dengue cases in bordering endemic countries and negatively with the days necessary for transmission (DNT) during the previous autumn in the central region of the country. Annual epidemic intensity in the period 1999-2016 was associated with DNT during previous autumn and winter. Regarding the spatio-temporal approach, dengue cases within a district were also associated with mild conditions in the previous autumn along with the number of dengue cases in neighboring countries. As for the spatial approach, the best model for the occurrence of two or more dengue cases per district included autumn minimum temperature and human population as fixed factors, and Province as a grouping variable. Explanatory power of all models was high, in the range 57-95\%.

Discussion. Given the epidemic nature of dengue in Argentina, virus pressure from endemic neighboring countries along with climatic conditions are crucial to explain disease dynamics. In the three methodological approaches, temperature conditions during autumn were best associated with dengue patterns. We propose that mild autumns represent an advantage for mosquito vector populations and that, in temperate regions, this advantage manifests as a larger egg bank from 
51 which the adult population will re-emerge in spring. This may constitute a valuable anticipating 52 tool for high transmission risk events.

53

54

55

56

57

58

59

60

61

62 63

64

65

66

67

68

69

70

71

\section{Introduction}

Dengue is a mosquito-borne infectious disease caused by a virus with four serotypes (DEN 1-4) of the Flaviviridae family, which is transmitted to man by the bite of mosquitoes of the genus Aedes, mainly Aedes aegypti in urban areas (Kramer et al., 2015). Clinical manifestations of the disease vary widely from asymptomatic to high fevers, headache, muscle and joint pain, and in some severe cases plasma leakage, hemorrhages and death (Polwiang, 2016). It stands as one of the main emergent tropical diseases, affecting 390 million people per year and a tenfold at risk in 128 countries, with an estimated annual global cost of US\$8.9 billion (Bhatt et al., 2013; Brady et al., 2012; Shepard et al., 2016). The major disease burden is registered in South East Asia, South Asia and Latin America; during 2016, over 2.3 million cases were reported only in the Americas, with 244.8 cases every 100,000 inhabitants (PAHO, 2018).

Where dengue is epidemic, the occurrence of an outbreak depends on virus arrival, the presence of a susceptible human population, a competent vector population and adequate environmental conditions for virus development and transmission. Therefore, dengue dynamics is affected by multiple mechanisms, in which temperature is an important determinant of mosquito traits relevant to transmission, namely the biting rate, egg and immature development, adult survival and fecundity, and development time of the virus in the mosquito (reviewed in Mordecai et al., 2017). While both seasonal and inter-annual climatic variability influence the geographical distribution of Ae. aegypti, other factors also determine habitat suitability. Importantly, the successful exploitation of artificial containers as larval habitats, which translates in a high domestic condition of the vector, allows Ae. aegypti to persist in regions that may otherwise be unsuitable based solely on climate (Jansen \& Beebe, 2010). Along with local climate, El Niño Southern Oscillation has also been reported to play a role in dengue dynamics at the seasonal and inter-annual scales (e.g. Vincenti-Gonzalez et al., 2018).

In Argentina, Ae. aegypti is distributed along temperate and subtropical latitudes (Vezzani \& Carbajo, 2008). Adult activity is concentrated in the warm season throughout its distribution and is absent during winter in temperate zones (Carbajo \& Vezzani, 2015). As 
82 neighboring countries to the northeast (Brazil and Paraguay) and northwest (Bolivia) are 83 endemic for dengue, Argentina represents the southern limit of dengue transmission in South 84 America with epidemic outbreaks concentrated in the warm season (November to May) 85 (Carbajo, Cardo \& Vezzani, 2012). In this transmission fringe, dengue re-emerged in 1998 86 causing epidemic outbreaks of different magnitudes in tight association with the incidence in 87 endemic neighboring countries (Fig. 1). Before 2016, the biggest outbreak had occurred in 2009, 88 with nearly 27,000 cases of DEN 1, followed by 2013, in which 2,922 cases were reported and 89 co-circulation of DEN 1, 2 and 4 was verified (MSN, 2015). In 2016, the biggest dengue 90 epidemic in the country so far was experienced, concomitant with first to date autochthonous transmission of Zika and chikungunya (26 and 322 confirmed cases, respectively) (MSN, 2016). Also, a recent outbreak of yellow fever has been reported in Brazil with over 1,000 confirmed cases (Ministério da Saúde do Brasil, 2018). These arboviruses are all transmitted in urban settings by the same mosquito vector, Ae. aegypti (Kramer et al., 2015). There is currently no antiviral therapy against dengue, and although the vaccine CYD-TDV "Dengvaxia ${ }^{\circledR}$ " has been approved in the country (ANMAT, 2017), the development of haemorragic dengue in a first infection after vaccination has been recently reported (WHO, 2017). Therefore, preventing contact between mosquitoes and people is still considered the main tool in the struggle against dengue.

Despite its recent history of epidemics, several studies with different geographic scopes have been performed to study dengue dynamics in Argentina. The spatio-temporal pattern of dengue cases during the 2009 epidemic has been analyzed within a city (Seijo et al. 2009; Estallo et al. 2014) and at the country scale (Carbajo, Cardo \& Vezzani, 2012). Regarding the 2016 outbreak, studies have been undertaken only at the city scale (Rotela et al., 2017; Carbajo et al., 2018). As no country-wide comprehensive analysis has been performed so far, and given the recent upsurge of the disease, the objective of this work was to identify the environmental factors

107 that trigger epidemic events in Argentina, by analyzing the spatio-temporal pattern of dengue cases since the re-emergence of the disease. 


\section{Materials \& Methods}

112 Mainland Argentine extends from $22^{\circ}$ to $55^{\circ} \mathrm{S}$, encompassing subtropical and temperate

113 latitudes (Fig. 2). Along with its neighboring countries, it is located between the two great oceans

114 of the Southern Hemisphere, the Atlantic and Pacific Oceans. This configuration reduces daily 115 and annual thermal amplitudes in comparison to similar latitudes of the Northern Hemisphere.

116 The Andes Mountains, with a height range of 2,600 - 6,000 m.a.s.1., also greatly influences the

117 regional climate by preventing the passage of moisture from the Pacific Ocean (Barros et al., 118 2015).

119 Mean temperature has increased by about $0.5^{\circ} \mathrm{C}$ across most of Argentina during the past 120 century. The strongest positive changes since 1960 occurred in the mean summer minimum 121 temperature, even though in this season the mean maximum temperatures mostly decreased, 122 except in Patagonia. In the second half of the past century, there was a general warming in

123 Patagonia where both the maximum and the minimum temperature had a positive trend that was 124 consistent with a more frequent northern flow component in the low levels of the atmosphere. 125 Regarding precipitation, annual positive trends in northern Argentina can be partly attributed to 126 variations in the frequency and intensity of the El Niño-Southern Oscillation (ENSO) phases. 127 The rest of subtropical Argentina was influenced by the southern shift of the western edge of the 128 South Atlantic high that enhanced moist advection from the Atlantic Ocean (Barros et al., 2015). 129 Information on dengue cases was obtained from dengue notifications reported in the 130 National Health Surveillance System. During laboratory surveillance (SIVILA), diagnosis was 131 confirmed through the detection of viral genome by polymerase chain reaction or detection of 132 neutralizing antibodies (IgG) by plaque reduction neutralization test (PRNT). After the onset of 133 epidemics in a given city, cases were further confirmed by detection of virus-specific 134 immunoglobulin $\mathrm{M}(\operatorname{IgM})$ antibodies or NS1 antigen detection. Unknown data regarding 135 department and province of residence was reconstructed using different sources: 1) district and 136 locality in the domicile section of the SIVILA database; 2) direct consultation with the provincial 137 Health Surveillance Area referents; or 3) data of province and district of sample collection 138 consigned in SIVILA. Data of province or country of contagion was reconstructed from 139 epidemiological comments of each case report. Cases registered in the SIVILA database were 140 classified as autochthonous or imported according to the site of acquisition of the infection. All 141 cases whose possible site of infection coincided with the jurisdiction of the patient's habitual 
142 residence, without a history of travel to an area with dengue virus circulation, were defined as

143 autochthonous. All cases with residence in an area without dengue virus circulation and with a

144 history of travel to an area with circulation of the dengue virus in the last 15 days prior to the

145 onset of symptoms were defined as imported. The database was available per district and 146 epidemiological week.

147 For all analyses hereafter epidemiological years were defined as from 1 July Year 1

148 through 30 June Year 2 (e.g., reference to Year 2004 includes the period from 07/01/2003 to

149 06/30/2004). In accordance, climatic seasons were defined as follows: winter 1 Jul - 30 Sep,

150 spring 1 Oct - 31 Dec, summer 1 Jan - 31 Mar, autumn 1 Apr - 30 Jun.

152 Explanatory variables

153 The selection of explanatory variables was based on available data at the spatial and 154 temporal detail required along with previous knowledge of which factors may affect dengue 155 dynamics (see Carbajo, Cardo \& Vezzani, 2012). For instance, the distance to the nearest water 156 body has been described as a proxy for the need of people to store water in containers, which 157 eventually become larval habitats for Ae. aegypti, whereas human population increase or 158 decrease in a given locality may reflect habitational and urbanization processes also associated 159 with the generation of potential immature habitats. Variables included were divided in four 160 classes: climatic, epidemiologic, geographic and demographic (definition of variables, units and 161 data sources are shown in Table 1, Pearson's correlation coefficients between pairs of variables 162 in Suppl File 1).

163 Climatic variables were calculated based on the Global Surface Summary of the Day, 164 downloaded from NOAA Satellite and Information Service (NCDC, 2016). This data is derived 165 from the Integrated Surface Hourly (ISH) dataset, which includes global data obtained from the 166 USAF Climatology Center and considers a minimum of 4 observations per day. We downloaded 167 daily values from 33 country-wide meteorological stations throughout the country (Fig. 2), which 168 presented no missing values for periods longer that 15 consecutive days along the period 1999169 2016. To calculate country-wide annual and seasonal values, daily records of all meteorological 170 stations located contiguous to case positive districts for at least one year were averaged (Fig. 2). 171 We considered this subset of 15 stations because in such locations, conditions for the occurrence 172 of cases are guaranteed, i.e. the vector is present in the district (Vezzani \& Carbajo, 2008) and 
173 virus transmission has been reported. Also, three regions were defined following the criterion of

174 dengue cases recompilation of the National Ministry of Health (center, east and west, Fig. 2) and

175 values of the stations within each region were averaged. To obtain single mean values of

176 temperature, precipitation, dew point and wind speed per district, monthly means from the period

177 July 2011- June 2016 were averaged for each of the 33 meteorological stations. Such values were

178 interpolated for the whole country (inverse weighted distance method, $15 \mathrm{~km}$ square cell grid)

179 and the grid value corresponding to the centroid of each district was extracted and taken as the

180 value for the district. For this interpolation, eight fictitious stations were added at the

181 northwestern limit of the country, in the high Andes range, which were assigned the lowest

182 values in the lowlands for each climatic variable. As no stations are present in the region, low

183 values were needed to limit the interpolation to the west.

184 The extrinsic incubation period (EIP) of the dengue virus in the mosquito is the lapse

185 from ingestion of infected blood to the virus transmission in a subsequent feed, and varies as a

186 function of temperature (Morin et al., 2013). The proportion of the EIP completed per day was

187 calculated for each meteorological station using a temperature dependent model in two hour

188 intervals based on an asymmetric interpolation of the daily maximum and minimum (Carbajo,

189 Cardo \& Vezzani, 2012). The function is inhibited by low and high temperatures (around 0 and

$19040^{\circ} \mathrm{C}$ respectively, details in Suppl File 2). With this information, two metrics were estimated.

191 The days of possible transmission (DPT) is the number of days per year that the EIP could be

192 completed before the death of the vector. It adds up the proportion of daily virus development for

193 a number of days equal to the mosquito life expectancy. If unity is reached it is assigned a value

194 of 1 , and 0 otherwise (Carbajo, Cardo \& Vezzani, 2012). This metric has the caveat of having to

195 define a life expectancy, which was set to 15 days based on a previous study (Carbajo et al.,

196 2001). A value for each district was obtained using the same methodology as for climatic

197 variables described above. The second metric counts the number of days necessary for

198 transmission (DNT). Beginning in each day of the year, the proportion of daily virus

199 development is added up until unity is reached, a lower DNT value indicating higher

200 transmission risk. It was resumed by its monthly and seasonal mean for each of the 15

201 meteorological stations, all values were averaged and also regional (center, east and west) values

202 were calculated. The relation among DNT, DPT and mean temperature is shown in Suppl. File 3. 

the models by means of the monthly Oceanic Niño Index 3.4 (5N-5S, 120E-170W), estimated as 205 a trimester mobile mean (NOAA, 2017). This index, which captures SST anomalies in the central equatorial Pacific, presents a unique value for the entire country. A El Niño event occurs when this anomaly is positive (above $0.5^{\circ} \mathrm{C}$ ) and a La Niña event occurs when it is negative (below $-0.5^{\circ} \mathrm{C}$ ) (Dogliotti, Ruddick \& Guerrero, 2016). We considered the sum of the index for six and twelve months as a relative indicator of the magnitude of such events, considering different time spans and moments of the previous year (see Table 1).

Last national censuses of human population by locality were performed in 2001 and 2010

212 (INDEC, 2017). Two demographic variables were considered, namely the population number per

213 district and the proportion of population change between both censuses, calculated as (population 214 in 2010 - population in 2001)/population in 2001 (Carbajo, Cardo \& Vezzani, 2012).

215 The number of dengue cases in bordering countries with endemic transmission was 216 obtained for the whole country in the case of Bolivia and Paraguay (PAHO, 2015). Given its 217 extension, the number of cases in Brazil was calculated considering only the three southernmost 218 districts that limit with Argentina (Santa Catarina, Rio Grande do Sul and Parana, Ministério da 219 Saúde do Brasil, 2017). As information was available at the annual scale in the traditional 220 definition (1 January - 31 December), annual cases corresponding to the current year were used 221 (e.g. cases in 2004 for the Year 2004).

223 Statistical modeling

224 Generalized Linear Mixed Models (GLMM) can treat data with errors that do not follow 225 a normal distribution, and include random terms (grouping variables) to account for temporal or 226 spatial correlation. Error distribution was selected in each analysis according to the definition of 227 the response variable (Gaussian, Poisson or dichotomic binomial). First, univariate analyses were 228 run (results in Suppl File 4). Then, a forward stepwise procedure was performed in which 229 centered explanatory variables were entered one-by-one, along with quadratic relations and two230 way interactions. Colinearity issues were first assessed considering correlation matrices (Suppl 231 File 1) and further tested in every step of the modelling with the variance inflation factors (VIF, 232 Car package). If any of the VIF values was higher than 5, which indicates multicolinearity (Zuur, 
233 Ieno \& Elphick, 2009), the variable with the highest VIF was dropped, all VIFs were 234 recalculated and the process was repeated until all values were lower than 5.

235 Once the best fixed model was achieved, the Province, District or Year (according to the

236 scope of each methodological approach) were tested as random intercepts or slopes. Decision 237 rules for random factor addition and variables inclusion were based on the Akaike's information 238 criterion (AIC) (Akaike, 1974); the model that yielded the lowest AIC was selected from all 239 possible models (Zuur et al., 2009). Graphical verification of the residuals was performed to 240 verify the assumptions of the models.

241 For Gaussian and Poisson distributions, the percentage of explanation achieved was 242 calculated as the deviance explained by the selected model divided by the deviance of the null 243 model. For dichotomic models, as the output variable of the binomial model lies between 0 and 244 1, a threshold probability must be selected to distinguish positivity from negativity (dengue 245 occurrence and absence, respectively). All possible cut-off points from 0.01 to 0.99 were 246 assessed to select an optimum cut-off point (cp) which maximized the classification effectiveness 247 of the model. This was evaluated by applying the Kappa index (K) to assess improvement of 248 classification of the model over chance (Fielding \& Bell, 1999). Finally, for models including a 249 random factor, variance percentages explained by the fixed (marginal $\mathrm{R}^{2}$ ) and fixed + random 250 (conditional $\mathrm{R}^{2}$ ) terms were calculated (MuMIn Package).

251 To analyze the yearly temporality and spatial distribution of dengue cases in Argentina 252 along the period 1999-2016, three methodological approaches were followed: (1) the temporal 253 approach aimed to identify the years in which the most important outbreaks occurred in 254 association with environmental variables and propose a risk estimation for future epidemics; (2) 255 the spatio-temporal approach intended to identify which variables explain the occurrence of 256 local outbreaks through time, taking into consideration the spatial variation country-wide; and 257 (3) the spatial approach put particular emphasis in the 2016 epidemics, to describe the 258 geographical distribution of dengue cases and identify its environmental drivers.

259

260

Temporal approach

261 For this analysis, two data sets were defined:

262 Ta. Annual cumulative number of dengue cases at the country level between 2009 and 2016. The 263 response variable was $\log$ ( $\mathrm{n}^{\mathrm{o}}$ of cases), modeled in a GLM with Gaussian error distribution (link 
264 identity) as a function of climatic variables and dengue cases in bordering countries (Table 1).

265 This period presents the best quality in surveillance data. Before the 2009 epidemics, records had 266 lower standards.

$267 \mathrm{~Tb}$. Annual cumulative number of dengue cases at the country level between 1999 and 2016. 268 Acknowledging different surveillance data quality, the analysis of this dataset attempted to 269 predict the risk of future outbreaks including all available information. Given that the number of 270 cases presents a random component and too much dispersion, the response variable was 271 classified in 4 categories of epidemic intensity: 0 (0 cases), 1 (1-1,000), 2 (1,001-5,000), 3 $272(>5,000)$ (Fig. 1). The model presented a Poisson error distribution and log link. Explanatory 273 variables describing El Niño events during the summer and dengue cases in bordering countries 274 were excluded because the time span in which they are calculated restrict anticipating power.

275

276

Spatio-temporal approach

277

278

From a database available per week at the district level, we considered cases between 2009 and 2016 grouped by district and epidemiological year. This analysis was restricted to case 279 positive districts for at least one year and contiguous to any of the available 33 meteorological stations. The combination of both conditions resulted in a subset of 15 districts retained (squares in Fig. 2). Two alternative dichotomic response variables were defined. Of the first, a value of 1 was assigned to a district in a given year if $>20$ cases were reported that year, a value of 0 otherwise (30\% of the database is classified as positive; the number of positive district does not differ when considering the threshold between 15 and 20 cases). In the second, a value of 1 was assigned to a district in a given year if $>100$ cases were reported, a value of 0 otherwise $(20 \%$ of the database classified as positive). Both were modeled in a GLM with binomial error distribution and link logit. Explanatory variables included were climatic and cases in endemic neighboring countries (Table 1).

\section{Spatial approach}

The database consisted in the number of cases (between epidemiological weeks 43 of 2015 and 29 of 2016) per district for the whole country (503 districts in total). The response variable was the occurrence of two or more dengue cases per district (dichotomic) in a binomial GLM with logit link. Four districts with up to two reported cases located southwards of the 
295 geographical distribution of Ae. aegypti were deliberately excluded assuming a potential mistake 296 in the classification as autochthonous. Explanatory variables included were climatic, 297 demographic and geographic (Table 1).

\section{Results}

\section{Temporal approach}

The best model associated the (log transformed) number of dengue cases at the national scale between 2009 and 2016 (Ta) positively with the number of dengue cases in bordering endemic countries and negatively with the DNT during the autumn of the previous year in the central region of the country (Table 2). In other words, higher number of cases in Bolivia and south of Brazil were correlated with more intense outbreaks in Argentina, and when a given autumn presented fewer days necessary for transmission, a larger outbreak could be expected the following warm season. The latter result makes sense for the central temperate region, in which temperature is a limiting factor for vector development, whereas in northern subtropical areas DNT values are consistently smaller. The model explained $95.2 \%$ of the variability of the data, and the correlation between the response values and those predicted by the model was 0.97. However, the model required 3 parameters for explaining only 8 values. No retro extrapolation

313 of this model to the years 1999-2008 could be performed, given that no reports of dengue cases 314 in Bolivia were available for those years.

315 When aiming to propose a model able to predict future dengue epidemics, considering the entire time span of epidemics since vector re-invasion $(\mathrm{Tb})$ and deliberately excluding variables with no predicting power, the best model associated the intensity of epidemics with temperature conditions during the previous autumn and winter, estimated as days of possible transmission for each season (Table 2). Although at lower explanation percentages (57\%), once again the meteorological situation during the previous autumn was a significant predictor of the following outbreak. This model is valuable in providing a risk estimation for the following warm season based on in advance and easily available climatic data as only input. The model predicted an probable cases up to epidemiological week 28, MSN, 2017). 
326

327

328

329

330

331

332

333

334

335

336

337

338

339

340

341

342

343

344

345

346

347

348

349

350

351

352

353

354

355

\section{Spatio-temporal approach}

When considering $>20$ cases as an epidemic, the selected model classified the observed values $72 \%$ better than chance $(K=0.72)$, at a cut-off point of 0.38 . None of the tested grouping random factors (1|District, 1|Year and Year|District) significantly improved the model. DNT values in autumn months of the previous year (best represented by May) resulted determinant; once again, dengue cases within a district were associated with mild conditions during the previous autumn (that is, lower DNT values). High DNT during the spring also favored the occurrence of epidemics, along with the number of dengue cases in Bolivia and Paraguay (Table 2).

When considering $>100$ cases as an epidemic, the selected model classified the observed values $63 \%$ better than chance $(\mathrm{K}=0.63)$, at a cut-off point of 0.39 . No random factors were significant. Results were consistent with the former analysis and associated the occurrence of an epidemic with the DNT of the previous May, the intensity of outbreaks in neighboring countries (Bolivia and Brazil), and positively with human population density (Table 2).

\section{Spatial approach}

Out of the 503 districts in the country, 272 were negative for dengue cases in both major epidemics (2009 and 2016), whereas 73 reported one or more cases in both occasions. A strong increase in the number of positive districts was verified in 2016 compared to 2009, with 133 new districts reporting cases, and only 25 with the opposite behavior (Fig. 3). The relation autochthonous/imported cases was, however, very similar in both years, around 26 autochthonous cases per imported case $(47,894 / 1,850$ for 2016 and 26,923/ 1,000 for 2009). Although not reflected in the number of cases and districts affected, considering temperature conditions expressed in terms of days of possible transmission (DPT) the situation in 2009 was worse than in 2016 (isolines of 30 and 120 DPT spread further south and west, Fig. 3).

The best model for the occurrence of two or more dengue cases per district included autumn minimum temperature and human population (log scale) as fixed factors, and Province as a random grouping variable (Table 2). Mild temperatures during the previous autumn and higher population numbers were associated with the occurrence of dengue cases per district. Prediction accuracy of the observed values was $80 \%$ better than chance $(\mathrm{K}=0.8)$ at a cut off-point of 0.4 . 
356 Explanatory power of the fixed factors (marginal $\mathrm{R}^{2}$ ) was 0.74 , whereas including the random 357 factor (conditional $\mathrm{R}^{2}$ ) raised explanation to 0.86 .

358 The model published in Carbajo, Cardo \& Vezzani (2012) for the 2009 epidemics was re359 run using the occurrence of two or more dengue cases per district in 2016 as a response variable, 360 and the same explanatory variables that predicted the previous outbreak. These were the DPT, 361 distance to water courses, population number (log scale) and the percentage of population change 362 in the period 2001-2010 (last two national censuses). In Argentina, national censuses are 363 typically performed on a decadal basis; therefore, updating of the demographic variables was 364 unfeasible. The model was not very accurate in predicting the new cases $(\mathrm{K}=0.47$, correct 365 classification 0.7 , sensibility 0.4 , specificity 0.9 ). An alternative explanation for the low 366 predictive model is the difference in the origin of both epidemics. The one in 2009 came down 367 from Bolivia, whereas the latter 2016 outbreak was caused by an unusually high incidence in 368 north-eastern neighboring countries (Brazil and Paraguay). Also, unexpectedly two northeastern provinces did not communicate any cases during 2009 (Fig. 3A).

Conversely, the new model was re-run with the 2009 epidemics data. In this case, the predictive accuracy was high $(\mathrm{K}=0.71$ at a cut off point of 0.35$)$, however the fraction explained by the fixed factors was significantly reduced (marginal $R^{2}=0.45$ ), whereas the variance explained by the Province as a random grouping increased (conditional $\mathrm{R}^{2}=0.84$ ).

374

375

376

377

378

379

380

381

382

383

384

385

\section{Discussion}

Modeling disease outbreaks in time and space is a powerful tool to qualitatively predict future potential epidemics (Myers et al., 2000). Given the epidemic nature of dengue in Argentina, virus pressure from endemic neighboring countries along with climatic conditions are crucial to explain disease dynamics. Remarkably, in all three methodological approaches used to analyze the spatial and temporal pattern of dengue cases, different proxies for temperature of the previous autumn were among the best predictors. The number of days necessary for transmission presented higher explanatory power than the raw variable in two approaches. Although this proxy is mainly used for transmission risk calculations, it may well resume conditions for the mosquito. As temperatures seldom reach extreme inhibition values during autumn, the temporal 
386 detail and the inclusion of temperature amplitude in its calculation may favor DNT instead of 387 mean temperature.

388 We built a temporal model based on the period 2009-2016, which lacks predictive power 389 because it relies on the ongoing year virus pressure from endemic neighboring countries. 390 However, it does provide a hint regarding the conditions of the previous autumn. If the autumn 391 of a given year is propitious for transmission, caution should be taken for the following summer 392 and the situation in bordering endemic areas should be followed up closely. We propose that 393 mild autumns represent an advantage for mosquito vector populations. In temperate regions with 394 no mosquito reproduction during winter, this advantage could manifest as a larger egg bank 395 deposited during autumn from which the adult population will re-emerge in spring. Including information of the years 1999-2008, we reached a model only relying on in advance climatic conditions. In this way, with easy-available temperature data we can anticipate 398 if the following year will present an epidemic of mid-high intensity. Models predicting epidemic intensity rather than number of cases are more robust to particular and/or stochastic conditions of a given year. The presented model properly predicted the 2017 situation; however as only two 401 major outbreaks (2009 and 2016) have occurred so far in Argentina to train the models, more time is needed to test its efficiency.

Spatio-temporal models of dengue cases distribution between 2009 and 2016 presented significant association with the same type of variables, prioritizing the days necessary for transmission during autumn months and the incidence in neighboring endemic countries. These models also lack predictive power and are particularly sensitive to the characteristics of the on course epidemics. This could also be appreciated when comparing 2009 and 2016 spatial models, in light of the poor correspondence in terms of numbers and geographical distribution of positive districts that presented the Carbajo, Cardo \& Vezzani (2012) model for the 2009 epidemics to predict the situation in 2016. Both main dengue outbreaks in Argentina started in locations close

411 to endemic borders and further expanded to other localities, however their origin was different.

412 In 2009, the epidemic was triggered by high incidence in Bolivia, spreading south from the 413 northwest, whereas in 2016 it started in the northeast, due to high incidence in south Brazil and 414 Paraguay. For this reason, the proper identification of imported cases is especially relevant 415 during transmission onset. We also found no relation between El Niño events and dengue 416 patterns. It has been described that river flow of water courses located within the northeast region 
417 of the country are strongly affected by ENSO events, whereas those located in the northwest 418 region are not (Pasquini \& Depetris, 2007). This may partly explain the lack of association of 419 dengue outbreaks and El Niño in Argentina, as described elsewhere, however we were unable to 420 test this hypothesis due to the short history of northeast and northwest derived epidemics in the 421 country.

422 The geographic distribution of dengue positive districts during the 2016 epidemics was 423 positively associated with minimum autumn temperature and human population, the latter 424 variable being also associated with the 2009 outbreak (Carbajo, Cardo \& Vezzani, 2012). A 425 larger human population number in a district may reflect higher virus pressure due to traveling. 426 Also, larger cities usually present precarious and overcrowded conditions, and are therefore more 427 susceptible to experiencing an outbreak (Brunkard et al., 2004). This is combined with a large 428 number of artificial containers due to uncontrolled urbanization and land uses linked to urban areas (e.g. cemeteries, rubbish and tire deposits), which represent optimum habitats for immature vector development. Within the spatial model, the inclusion of Province as a random grouping factor may reflect non biological features, such as asymmetries in case records or in the efficiency of prevention and control interventions. The total absence of cases reports during 2009 in some northeastern provinces is an extreme example of this issue. These areas experienced unreported transmission, which could have substantially affected the predictability of the 2009 model as it occurred to Aström et al. (2012).

Comparing dengue distribution models may be problematic because of differing modeling approaches and scales, the diverse quality of the data used, and the selection of variables associated with disease distribution (Messina et al., 2015). Further issues arise in the particular case of Argentina due to its geography. It constitutes one of the potential areas of transmission expansion and intensification, where many models do not agree in their predictions

441 (Messina et al., 2015). It extends along 3,800 km including a gradient of transmission risk due to 442 climatic variables roughly decreasing from north to south, but almost a third of the population 443 lives at the transmission fringe in the center-east of the country. The epidemic inter-annual 444 pattern is irregular, with frequent virus circulation in the north and large sporadic outbreaks 445 extending to almost half of the country. This implies that the maximum geographic extension 446 does not repeat regularly and may respond to particular conditions occurring in certain years. 447 Global models are not aimed at identifying these particular events, what would need a spatial and 
448 temporal detail not yet implemented or simply not available globally. Although the inclusion of 449 demographic and socio-economic factors has improved global models (e.g., Aström et al., 2012; 450 Mordecai et al., 2017), its application in Argentina would require a district detail to account for 451 the internal heterogeneity in, for example, the geographical distribution of income along the 452 country.

453 The systematic data gathering of dengue cases in a country-wide system allows for the 454 constant updating of the epidemiological situation, as well as the identification of high risk areas 455 to prioritize prevention and control measures both at the communitarian and individual levels. 456 The strength of the 2016 outbreak manifests the flaws of the mitigation strategies. This, in 457 conjunction with a higher dengue incidence in neighboring countries and the introduction of 458 other arboviruses transmitted by the same vector (Zika, chikungunya, and potentially yellow 459 fever), forecast a complex scenario which claims for an integrative research approach with joint 460 work from the areas of education, infrastructure and health. Along with the need to develop 461 better and faster diagnostic methods, we need to achieve consciousness in the population, whose 462 contribution is essential. The optimal use of models to inform policy decisions requires a 463 continuous dialogue between the multidisciplinary infectious disease dynamics community and decision makers (Heesterbeek et al., 2015), essential to plan and put into practice adequate prevention and control measures for each jurisdiction.

\section{Conclusion}

In the southernmost extreme of epidemic transmission in the Americas, the pattern of dengue cases concentrated during the warm season was associated with different proxies for temperature conditions during the previous autumn and virus pressure from neighboring endemic countries. This provides a valuable opportunity to prepare in advance for a qualitatively strong epidemic during the following summer if the autumn of a given year is propitious for transmission, and enable the onset of early alerts by close follow up of the situation in endemic bordering countries.

476 


\section{References}

479 Akaike H. 1974. A new look at the statistical model identification. IEEE Transactions on 480 Automatic Control 19:716-723.

481 ANMAT - Administración Nacional de Medicamentos, Alimentos y Tecnología Médica. 482 Programa de Evaluación de Tecnologías Sanitaria. 2017. Eficacia y seguridad de la vacuna 48 tetravalente

para dengue $\left(\right.$ Dengvaxia $\left.^{\mathrm{NR}}\right)$. Available at http://www.anmat.gov.ar/ets/ETS DENGUE agosto-EN2.pdf(accessed 25 September 2017)

485

486

487

488

489

490

491

492

493

494

495

496

497

498

499

500

501

502

503

505

506

504 Carbajo AE, Rubio A, Viani MJ, Colombo MR. 2018. The largest dengue outbreak in Argentina

Aström C, Rocklöv J, Hales S, Béguin A, Louis V, Sauerborn R. 2012. Potential distribution of dengue fever under scenarios of climate change and economic development. Ecohealth 9: 448454.

Barros VR, Boninsegna JA, Camilloni IA, Chidiak M, Magrín GO, Rusticucci M. 2015. Climate change in Argentina: trends, projections, impacts and adaptation. WIREs Climate Change 6:151169.

Bhatt S, Gething PW, Brady OJ, Messina JP, Farlow AW, Moyes CL, Drake JM, Brownstein JS, Hoen AG, Sankoh O, Myers MF, George DB, Jaenisch T, Wint GRW, Simmons CP, Scott TW, Farrar JJ, Hay SI. 2013. The global distribution and burden of dengue. Nature 496:504-507.

Brady OJ, Gething PW, Bhatt S, Messina JP, Brownstein JS, Hoen AG, Moyes CL, Farlow AW, Scott TW, Hay SI. 2012. Refining the global spatial limits of dengue virus transmission by evidence-based consensus. PLoS Neglected Tropical Diseases 6:e1760.

Brunkard JM, López JLR, Ramirez J, Cifuentes E, Rothenberg SJ, Hunsperger EA, Moore CG, Brussolo RM, Villarreal NA, Haddad BM. 2007. Dengue fever seroprevalence and risk factors, Texas-Mexico Border. Emerging Infectious Diseases 13:1477-1483.

Carbajo AE, Schweigmann N, Curto SI, De Garín A, Bejarán R. 2001. Dengue transmission risk maps of Argentina. Tropical Medicine \& International Health 6:170-183.

02 Carbajo AE, Cardo MV, Vezzani D. 2012. Is temperature the main cause of dengue rise in nonendemic countries? The case of Argentina. International Journal of Health Geographics 11:26. and spatial analyses of dengue cases in relation to a control program in a district with sylvan and urban environments. Asian Pacific Journal of Tropical Medicine 11:227-234. 
507 Dogliotti AI, Ruddick K \& Guerrero R. 2016. Seasonal and inter-annual turbidity variability in 508 the Río de la Plata from 15 years of MODIS: El Niño dilution effect. Estuarine, Coastal and 509 Shelf Science 182:27-39.

510 Estallo EL, Carbajo AE, Grech MG, Frías-Céspedes M, López L, Lanfri MA, Ludueña-Almeida

511 FF, Almirón WR. 2014. Spatio-temporal dynamics of dengue 2009 outbreak in Córdoba City, 512 Argentina. Acta Tropica 136:129-136.

513 Fielding AH, Bell JF. 1997. A review of methods for the assessment of prediction errors in 514 conservation presence/absence models. Environmental Conservation 24:38-49.

515 Heesterbeek H, Anderson R, Andreasen V, Bansal S, De Angelis D, Dye C, Eames KT, 516 Edmunds WJ, Frost SD, Funk S, Hollingsworth TD, House T, Isham V, Klepac P, Lessler J, 517 Lloyd-Smith JO, Metcalf CJ, Mollison D, Pellis L, Pulliam JR, Roberts MG, Viboud C. 2015. 518 Modeling infectious disease dynamics in the complex landscape of global health. Science 347: 519 aaa4339.

520 INDEC - Instituto Nacional de Estadísticas y Censos (2017). Available at:

521 https://www.indec.gob.ar/bases-de-datos.asp?solapa=5 (accessed 10 June 2017).

522 Kraemer MUG, Sinka ME, Duda KA, Mylne AQN, Shearer FM, Barker CM, Moore CG, 523 Carvalho RG, Coelho GE, Van Bortel W, Hendrickx G, Schaffner F, Elyazar IRF, Teng H-J, 524 Brady OJ, Messina JP, Pigott DM, Scott TW, Smith DL, Wint GRW, Golding N, Hay SI. 2015. 525 The global distribution of the arbovirus vectors Aedes aegypti and Ae. albopictus. Elife 4:1-18.

526 McCullagh P, Nelder JA. 1989. Generalized Linear Models. London: Chapman \& Hall.

527 Ministério da Saúde do Brasil. 2017. Available at: 528 http://portalsaude.saude.gov.br/index.php/situacao-epidemiologica-dados-dengue (accessed 1 529 June 2017)

530 Messina JP, Brady OJ, Pigott DM, Golding N, Kraemer MU, Scott TW, Wint GR, Smith DL, 531 Hay SI. 2015. The many projected futures of dengue. Nature Reviews Microbiology 13: 230-239.

532 Ministério da Saúde do Brasil. 2018. Monitoramento do Período Sazonal da Febre Amarela

533 Brasil - 2017/2018. http://portalarquivos2.saude.gov.br/images/pdf/2018/abril/19/Informe-FA-

534 22.pdf (accessed 23 April 2018).

535 Mordecai EA, Cohen JM, Evans MV, Gudapati P, Johnson LR, Lippi CA, Miazgowicz K, 536 Murdock CC, Rohr JR, Ryan SJ, Savage V, Shocket MS, Stewart Ibarra A, Thomas MB, Weikel 
537 DP. 2017. Detecting the impact of temperature on transmission of Zika, dengue, and 538 chikungunya using mechanistic models. PLoS Neglected Tropical Diseases 11: e0005568.

539 Morin CW, Comrie AC, Ernst K. 2013. Climate and dengue transmission: evidence and 540 implications. Environmental Health Perspectives 121:1264-1272.

541 MSN - Ministerio de Salud de la Nación. 2009. Dirección de Epidemiología. Área de Análisis y

542 Monitoreo de la Salud. Situación del dengue en Argentina. Primer semestre del 2009. Vol. 44,

543 Boletín Epidemiológico Periódico. Buenos Aires.

544 MSN - Ministerio de Salud de la Nación. 2015. Dirección de Epidemiología. Área de vigilancia.

545 Vigilancia de dengue y otros arbovirus. Boletín Integrado de Vigilancia 275 SE 36 (eISSN 2422546 698X).

547 MSN - Ministerio de Salud de la Nación. 2016. Dirección de Epidemiología. Área de vigilancia.

548 Vigilancia de dengue y otros arbovirus. Boletín Integrado de Vigilancia 327 SE 37 (eISSN 2422-

549 698X). Available at: http://www.msal.gob.ar/images/stories/boletines/Boletin-Integrado-De-

$550 \quad$ Vigilancia-N327-SE37.pdf (accessed 1 March 2017)

551 MSN - Ministerio de Salud de la Nación. 2017. Dirección de Epidemiología. Área de vigilancia.

552 Vigilancia de dengue y otros arbovirus. Boletín Integrado de Vigilancia 370 SE 30 (eISSN 2422-

553 698X). Available at:

554 http://www.msal.gob.ar/images/stories/boletines/boletin integrado_Vigilancia_N370-SE30.pdf

555 (accessed 30 July 2017)

556 Myers MF, Rogers DJ, Cox J, Flahault A, Hay SI. 2000. Forecasting disease risk for increased 557 epidemic preparedness in public health. Advances in Parasitology 47:309-330.

558 NCDC - National Climatic Data Center. 2016. Climate Data Online. Available at:

559 https://www7.ncdc.noaa.gov/CDO/cdoselect.cmd?datasetabbv=GSOD\&countryabbv=\&georegio

560 nabbv $=($ accessed 18 February 2017)

561 NOAA - National Oceanic and Atmospheric Administration. 2017. El Niño / Southern

562 Oscillation (ENSO). Cold and warm episodes by season. Available at

563 http://www.cpc.ncep.noaa.gov/products/analysis_monitoring/ensostuff/ensoyears.shtml

564 (accessed 18 March 2017)

565 PAHO - Pan American Health Organization. 2018. Descripción de la situación epidemiológica

566 actual del dengue en las Américas. Available at 
567 http://www.paho.org/hq/index.php?option=com_topics\&view=readall\&cid=3274\&Itemid=4073

568 4\&lang=es (accessed 20 April 2018)

569 Pasquini AI, Depetris PJ. 2007. ENSO-triggered exceptional flooding in the Parana River: where

570 is the excess water coming from? Journal of Hydrology 383:186-193.

571 Polwiang S. 2016. Estimation of dengue infection for travelers in Thailand. Travel Medicine and 572 Infectious Disease 14:398-406.

573 Rotela C, Lopez L, Frías Céspedes M, Barbas G, Lighezzolo A, Porcasi X, Lanfri MA, Scavuzzo 574 CM, Gorla DE. 2017. Analytical report of the 2016 dengue outbreak in Córdoba city, Argentina. 575 Geospatial Health 12:564.

576 Seijo A, Romer Y, Espinosa M, Monroig, Giamperetti S, Ameri D, Antonelli L. 2009. Brote de

577 dengue autóctono en el área metropolitana Buenos Aires. Experiencia del Hospital de 578 Enfermedades Infecciosas F. J. Muñiz. Medicina (B. Aires) 69(6).

579 Shepard DS, Undurraga EA, Halasa YA, Stanaway JD. 2016. The global economic burden of 580 dengue: a systematic analysis. The Lancet Infectious Diseases 16:935-941.

581 van Panhuis WG, Marc Choisy, Xin Xiong, Nian Shong Chok, Pasakorn Akarasewi, Sopon 582 Iamsirithaworn, Lam SK, Chong CK, Lam FC, Phommasak B, Vongphrachanh P, Bouaphanh K, 583 Rekol H, Hien NT, Thai PQ, Duong TN, Chuang J-H, Liu Y-L, Ng L-C, Shi Y, Tayag EA, 584 Roque Jr. VG, Suy LLL, Jarman RG, Gibbons RV, Velasco JMS, Yoon I-K, Burke DS, 585 Cummings DAT. 2015. Region-wide synchrony and traveling waves of dengue across eight 586 countries in Southeast Asia. Proceedings of the National Academy of Sciences 112:13069.

587 Vezzani D, Carbajo AE. 2008. Aedes aegypti, Aedes albopictus, and dengue in Argentina: 588 current knowledge and future directions. Memorias Instituto Oswaldo Cruz 103:66-74.

589 Vincenti-Gonzalez MF, Tami A, Lizarazo EF, Grillet ME. 2018. ENSO-driven climate 590 variability promotes periodic major outbreaks of dengue in Venezuela. Scientific Reports 8:5727. 591 WHO - World Health Organization. 2017. Updated Questions and Answers related to 592 information presented in the Sanofi Pasteur press release on 30 November 2017 with regards to 593 the dengue vaccine Dengvaxia ${ }^{\circledR}$ Available at:

594 http://www.who.int/immunization/diseases/dengue/q and a dengue vaccine_dengvaxia/en/

595 (accessed 1 November 2017)

596 Zuur A, Ieno E, Elphick C. 2009. A protocol for data exploration to avoid common statistical 597 problems. Methods in Ecology and Evolution 1:3-14. 
598 Zuur AF, Ieno EN, Walker NJ, Saveliev AA, Smith GM. 2009. Mixed effects models and 599 extensions in ecology with $R$. New York: Springer. 
Figure 1

Total number of dengue cases registered in Argentina per epidemiological Year (defined from 1 July Year X-1 to 30 June Year X) for the period 1999-2016, and classification of each Year in epidemic intensity 0 to 4

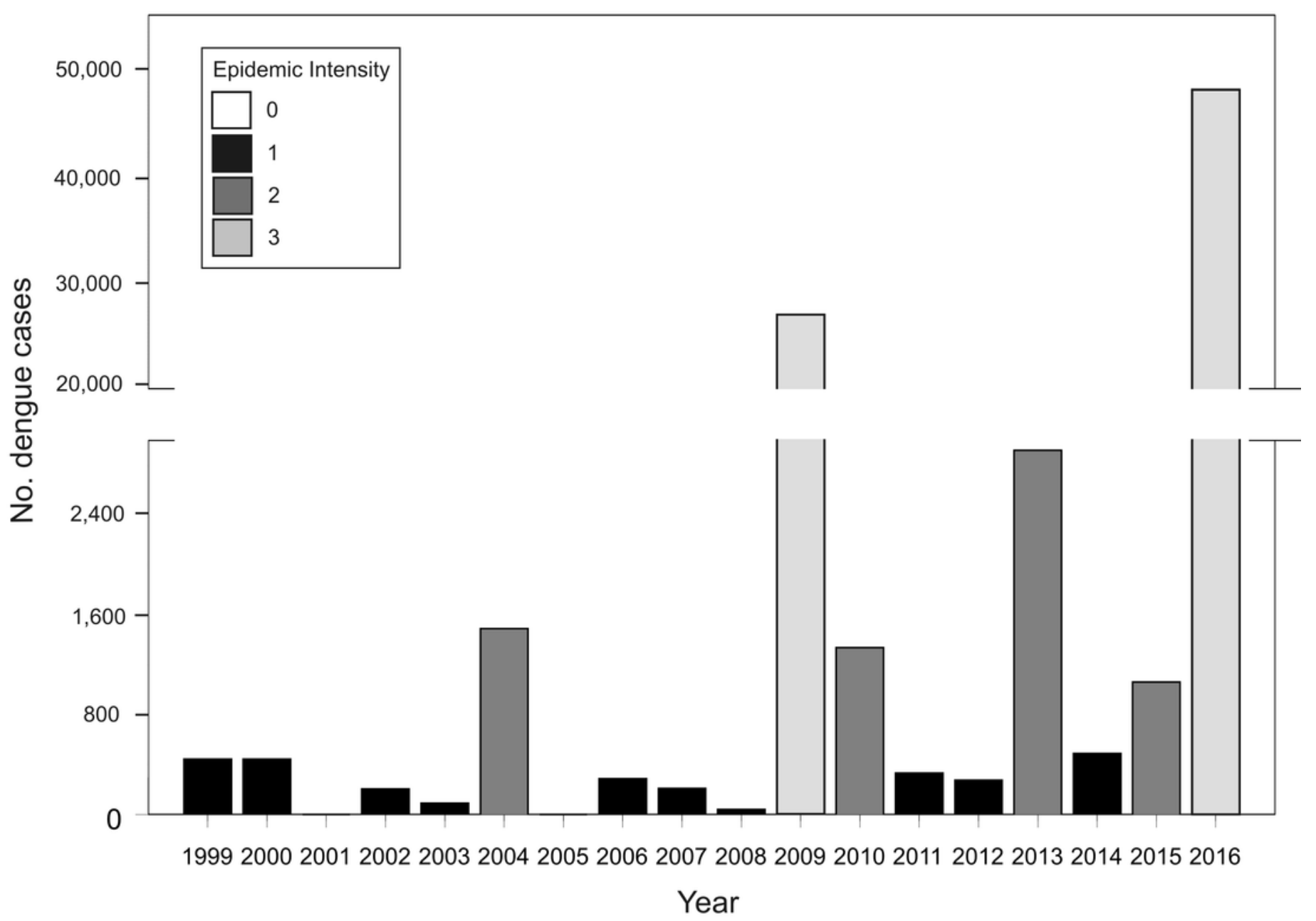




\section{Figure 2 (on next page)}

Study area and meteorological stations. Squares indicate stations adjacent to districts with dengue cases in at least one year since 2009. 


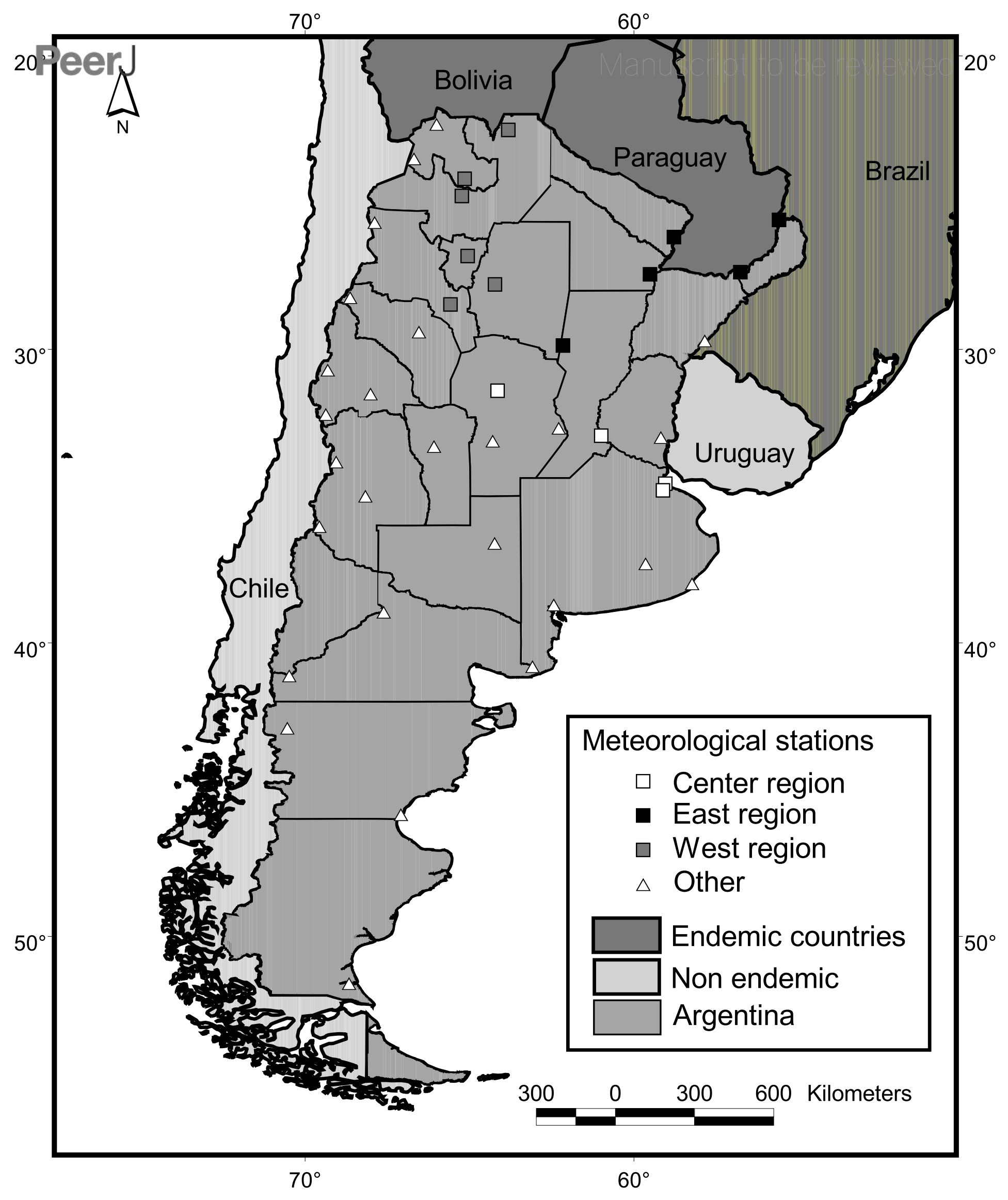


Figure 3 (on next page)

Dengue cases per district and days of possible transmission (DPT) isolines for 2009 (A) and 2016 (B). 

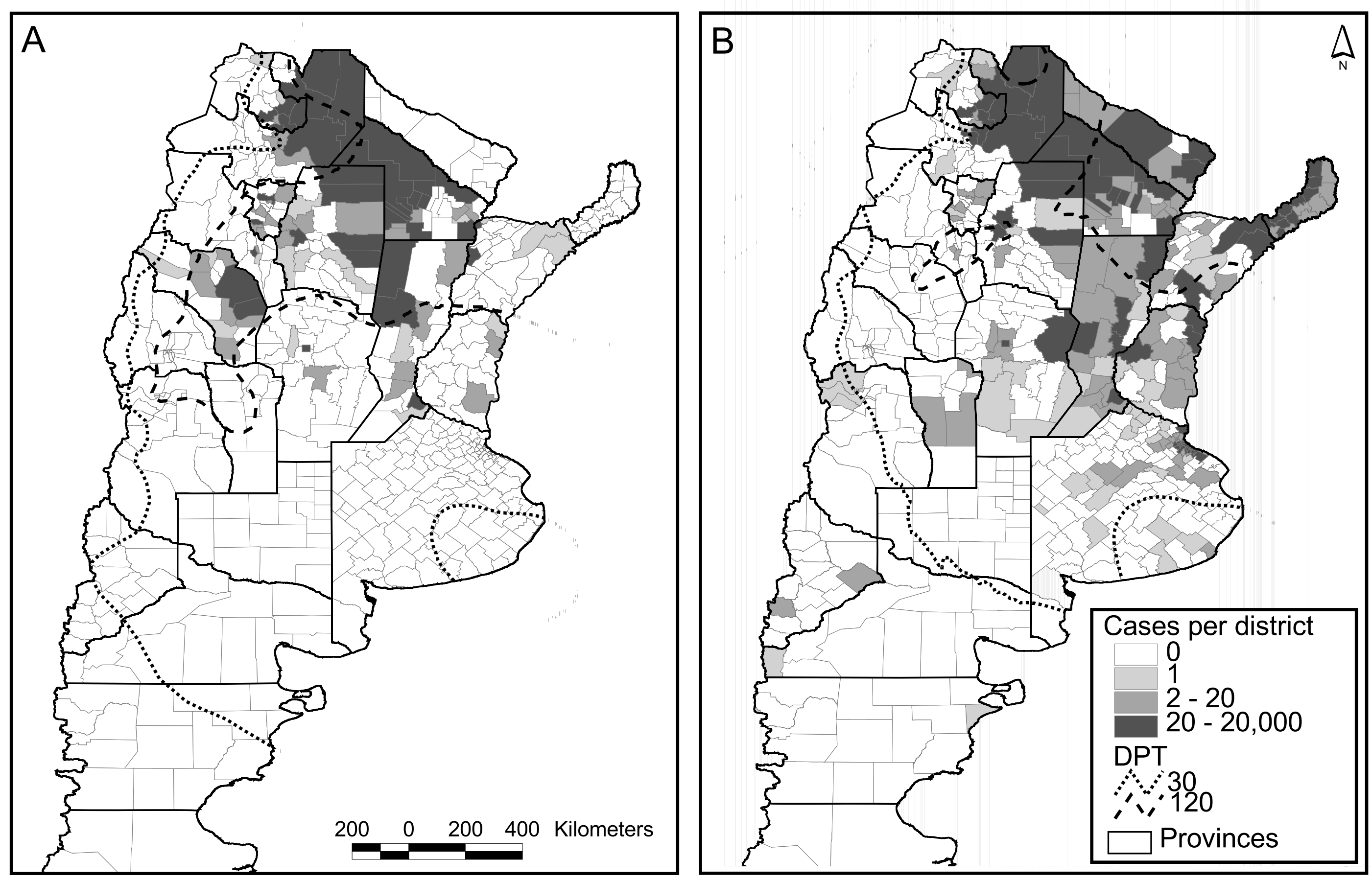


\section{Table $\mathbf{1}$ (on next page)}

Explanatory variables included in statistical models for temporal 2009-2016 (Ta), temporal 1999-2016 (Tb), spatio-temporal (ST) and spatial (S) methodological approaches. 


\begin{tabular}{|c|c|c|c|c|c|}
\hline Variable class & $\begin{array}{l}\text { Variable } \\
\text { Name }\end{array}$ & Description & Units & Source & $\begin{array}{l}\text { Included in } \\
\text { approach }\end{array}$ \\
\hline \multirow[t]{11}{*}{ Climatic } & Tme* & Mean temperature & ${ }^{\circ} \mathrm{C}$ & [1] & $\mathrm{Ta}-\mathrm{Tb}-\mathrm{ST}-\mathrm{S}$ \\
\hline & Tmi* & Minimum temperature & ${ }^{\circ} \mathrm{C}$ & {$[1]$} & $\mathrm{Ta}-\mathrm{Tb}-\mathrm{ST}-\mathrm{S}$ \\
\hline & PP & $\begin{array}{l}\text { Mean annual cumulative } \\
\text { precipitation }\end{array}$ & $\mathrm{mm}$ & {$[1]$} & $\mathrm{Ta}-\mathrm{Tb}-\mathrm{ST}-\mathrm{S}$ \\
\hline & $\mathrm{DE}$ & Mean annual dew point & ${ }^{\circ} \mathrm{C}$ & {$[1]$} & $\mathrm{Ta}-\mathrm{Tb}-\mathrm{ST}-\mathrm{S}$ \\
\hline & WI & Mean annual windspeed & $\mathrm{m} / \mathrm{s}$ & {$[1]$} & $\mathrm{Ta}-\mathrm{Tb}-\mathrm{ST}-\mathrm{S}$ \\
\hline & $\mathrm{DNT}^{*}$ & Days necessary for transmission & days & {$[1]$} & $\mathrm{Ta}-\mathrm{Tb}-\mathrm{ST}-\mathrm{S}$ \\
\hline & $\mathrm{DPT}^{*}$ & Days of possible transmission & days & {$[1]$} & $\mathrm{Ta}-\mathrm{Tb}-\mathrm{ST}-\mathrm{S}$ \\
\hline & $\mathrm{JnDe}$ & $\begin{array}{l}\text { sum of Niño monthly index for } \\
\text { the } 12 \text { months of the previous } \\
\text { year (e.g. Jan-Dec } 2000 \text { for year } \\
\text { 2001) }\end{array}$ & --- & {$[2]$} & $\mathrm{Ta}-\mathrm{Tb}-\mathrm{ST}$ \\
\hline & JnJn & $\begin{array}{l}\text { sum of Niño monthly index } \\
\text { from January through June of } \\
\text { the previous year. }\end{array}$ & --- & {$[2]$} & $\mathrm{Ta}-\mathrm{ST}$ \\
\hline & JIDe & $\begin{array}{l}\text { sum of Niño monthly index } \\
\text { from July-Dec of the previous } \\
\text { year }\end{array}$ & --- & {$[2]$} & $\mathrm{Ta}-\mathrm{ST}$ \\
\hline & ApSe & $\begin{array}{l}\text { sum of Niño monthly index } \\
\text { from April-Sept of the previous } \\
\text { year }\end{array}$ & --- & {$[2]$} & $\mathrm{Ta}-\mathrm{Tb}-\mathrm{ST}$ \\
\hline \multirow[t]{3}{*}{ Epidemiologic } & DenBol & $\begin{array}{l}\text { Number of dengue cases in } \\
\text { Bolivia }\end{array}$ & & {$[3]$} & $\mathrm{Ta}-\mathrm{ST}$ \\
\hline & DenPar & $\begin{array}{l}\text { Number of dengue cases in } \\
\text { Paraguay }\end{array}$ & & {$[3]$} & $\mathrm{Ta}-\mathrm{ST}$ \\
\hline & DenBra & $\begin{array}{l}\text { Number of dengue cases in } \\
\text { southern Brazil }\end{array}$ & & {$[4]$} & $\mathrm{Ta}-\mathrm{ST}$ \\
\hline \multirow[t]{6}{*}{ Geographic } & $\mathrm{Ar}$ & Area of each district & $\mathrm{m}^{2}$ & [5] & $\mathrm{S}$ \\
\hline & $\mathrm{Al}$ & $\begin{array}{l}\text { Mean district elevation above } \\
\text { sea level }\end{array}$ & $\mathrm{m}$ & {$[6]$} & $\mathrm{S}$ \\
\hline & $\mathrm{AlSd}$ & $\begin{array}{l}\text { Standard deviation of altitude of } \\
\text { all pixels within a district }\end{array}$ & $\mathrm{m}$ & {$[6]$} & $\mathrm{S}$ \\
\hline & DiWa & $\begin{array}{l}\text { Distance to the nearest water } \\
\text { body or course (excluding the } \\
\text { sea) }\end{array}$ & $\mathrm{Km}$ & {$[5]$} & $\mathrm{S}$ \\
\hline & DiBol & $\begin{array}{l}\text { Distance to nearest border } \\
\text { crossing to Bolivia }\end{array}$ & $\mathrm{Km}$ & {$[5]$} & $\mathrm{S}$ \\
\hline & DiNea & $\begin{array}{l}\text { Distance to nearest border } \\
\text { crossing to Brazil/Paraguay }\end{array}$ & $\mathrm{km}$ & {$[5]$} & $\mathrm{S}$ \\
\hline \multirow[t]{2}{*}{ Demographic } & Pop & Population per district & people & {$[7]$} & ST - S \\
\hline & Prc & $\begin{array}{l}\text { Percentage of population } \\
\text { change per district }\end{array}$ & --- & {$[7,8]$} & $\mathrm{S}$ \\
\hline
\end{tabular}


2 * Calculated at different time spans: epidemiological year, season (winter, spring, autumn) and

3 month. Also for each time span, regional (center, east and west) averages were calculated.

4 Data sources:

5 [1] National Climatic Data Center - NCDC (2016) Climate Data Online.

6 https://www7.ncdc.noaa.gov/CDO/cdoselect.cmd?datasetabbv=GSOD\&countryabbv=\&georegio

7 nabbv $=$

8 [2] National Oceanic and Atmospheric Administration - NOAA (2017) El Niño / Southern

9 Oscillation (ENSO). Cold and warm episodes by season.

10 http://www.cpc.ncep.noaa.gov/products/analysis_monitoring/ensostuff/ensoyears.shtml

11 [3] PAHO (2015) Descripción de la situación epidemiológica actual del dengue en las Américas.

12 http://www.paho.org/hq/index.php?option=com_content\&view=article\&id=4494\%3A2010-

13 descripcion-situacion-epidemiologica-actual-dengue-americas\&catid=1221\%3Adengue-

14 statistics-maps\&Itemid $=41505 \&$ lang $=\mathrm{pt}$

15 [4] Ministério da Saúde do Brasil (2017) http://portalsaude.saude.gov.br/index.php/situacao16 epidemiologica-dados-dengue

17 [5] United States Geological Survey (2005) Shuttle Radar Topography Mission, Digital Terrain 18 Elevation Data.

19 [6] Instituto Geográfico Nacional (2010) Sistema de Información Geográfica Nacional. Buenos 20 Aires.

21 [7] Instituto Nacional de Estadísticas y Censos - INDEC (2010) Censo Nacional de Población, 22 Hogares y Viviendas 2010. Available online: http://www.censo2010.indec.gov.ar/.

23 [8] Instituto Nacional de Estadísticas y Censos - INDEC (2001) Censo Nacional de Población, 24 Hogares y Viviendas 2001. Available online: http://www.indec.gov.ar/webcenso/index.asp. 25 26 


\section{Table 2 (on next page)}

Selected models for the different methodological approaches used to study the environmental and demographical determinants of dengue epidemics in Argentina. Asterisks next to the values indicate statistical significance ${ }^{*} p<0.05$, ${ }^{* *} p<0.01$, $* * * p<0.001$.

See variables abbreviations in Table 1. 


\begin{tabular}{|c|c|c|c|c|}
\hline \multicolumn{2}{|c|}{ Methodological approach } & \multirow{2}{*}{$\begin{array}{l}\text { Response variable } \\
\log \left(n^{\circ} \text { cases }\right)\end{array}$} & \multirow{2}{*}{$\begin{array}{l}\text { Explanatory variable } \\
\text { Ordinate }\end{array}$} & \multirow{2}{*}{$\begin{array}{l}\text { Estimate } \pm \text { standard error } \\
7.59 \pm 0.20 * * *\end{array}$} \\
\hline Temporal & $2009-2016$ & & & \\
\hline & & & $\mathrm{DNT}_{\text {autumn-center }}$ & $-1.11 \pm 0.25 *$ \\
\hline & & & DenBol & $1.85 \pm 0.29 * *$ \\
\hline & & & DenBra & $1.29 \pm 0.32 *$ \\
\hline & 1999-2016 & Epidemic intensity & Ordinate & $-0.01 \pm 0.28$ \\
\hline & & & $\mathrm{DNT}_{\text {autumn }}$ & $-0.78 \pm 0.28 * *$ \\
\hline & & & $\mathrm{DNT}_{\text {winter }}$ & $0.47 \pm 0.23 *$ \\
\hline \multirow{12}{*}{\multicolumn{2}{|c|}{ Spatio-temporal }} & Occurrence $>20$ cases & Ordinate & $-1.41 \pm 0.31 * * *$ \\
\hline & & & $\mathrm{DNT}_{\text {may }}$ & $-0.29 \pm 0.09 * *$ \\
\hline & & & DenBol & $0.07 \pm 0.02 * * *$ \\
\hline & & & $\mathrm{DNT}_{\text {spring }}$ & $0.33 \pm 0.13 * *$ \\
\hline & & & DenPar & $0.024 \pm 0.007 * * *$ \\
\hline & & & $\mathrm{DNT}_{\text {may }}:$ DenBol & $0.008 \pm 0.003 * *$ \\
\hline & & Occurrence $>100$ cases & Ordinate & $-2.35 \pm 0.45 * * *$ \\
\hline & & & $\mathrm{DNT}_{\text {may }}$ & $-0.29 \pm 0.10 * *$ \\
\hline & & & DenBol & $0.09 \pm 0.02 * * *$ \\
\hline & & & DenBra & $0.06 \pm 0.02 * * *$ \\
\hline & & & Pop (in thousands) & $0.0008 \pm 0.0004 *$ \\
\hline & & & $\mathrm{DNT}_{\text {may }}:$ DenBol & $0.006 \pm 0.002 *$ \\
\hline \multirow[t]{4}{*}{ Spatial } & & Occurrence $\geq 2$ cases & Ordinate & $-2.33 \pm 0.51 * * *$ \\
\hline & & & $\mathrm{Tmi}_{\text {autumn }}$ & $2.88 \pm 0.46 * * *$ \\
\hline & & & $\log ($ Pop $)$ & $2.49 \pm 0.32 * * *$ \\
\hline & & & (1|Province) & \\
\hline
\end{tabular}

